\title{
Self-Healing in Carbon Nitride Evidenced As Material Inflation and Superlubric Behavior
}

DOI:

10.1021/acsami.8b03055

\section{Document Version}

Accepted author manuscript

Link to publication record in Manchester Research Explorer

\section{Citation for published version (APA):}

Bakoglidis, K. D., Palisaitis, J., Dos Santos, R. B., Rivelino, R., Persson, P. O. Å., Gueorguiev, G. K., \& Hultman, L. (2018). Self-Healing in Carbon Nitride Evidenced As Material Inflation and Superlubric Behavior. ACS Applied Materials and Interfaces, 10(19), 16238-16243. https://doi.org/10.1021/acsami.8b03055

\section{Published in:}

ACS Applied Materials and Interfaces

\section{Citing this paper}

Please note that where the full-text provided on Manchester Research Explorer is the Author Accepted Manuscript or Proof version this may differ from the final Published version. If citing, it is advised that you check and use the publisher's definitive version.

\section{General rights}

Copyright and moral rights for the publications made accessible in the Research Explorer are retained by the authors and/or other copyright owners and it is a condition of accessing publications that users recognise and abide by the legal requirements associated with these rights.

\section{Takedown policy}

If you believe that this document breaches copyright please refer to the University of Manchester's Takedown Procedures [http://man.ac.uk/04Y6Bo] or contact uml.scholarlycommunications@manchester.ac.uk providing relevant details, so we can investigate your claim.

\section{OPEN ACCESS}




\title{
Self-healing in carbon nitride evidenced as material inflation and superlubric behavior
}

\author{
Konstantinos D. Bakoglidis ${ }^{* 1,2, I}$, Justinas Palisaitis ${ }^{2}$, Renato B. dos Santos ${ }^{3}$, Roberto Rivelino ${ }^{3}$, \\ Per O.A. Persson ${ }^{2}$, Gueorgui K. Gueorguiev², Lars Hultman*2. \\ ${ }^{1}$ School of Materials, The University of Manchester, Manchester, M13 9PL, UK.
}

${ }^{2}$ Thin Film Physics Division, Department of Physics (IFM), Linköping University, SE-581 83, Sweden.

${ }^{3}$ Instituto de Física, Universidade Federal da Bahia, 40210-340 Salvador, Bahia, Brazil.

KEYWORDS. superlubricity, carbon-based coatings, electron microscopy, wear, self-healing.

ABSTRACT. All known materials wear under extended mechanical contacting. Superlubricity may present solutions, but is an expressed mystery in C-based materials. We report negative wear of carbon nitride films; a wear-less condition with mechanically-induced material inflation at the nanoscale and friction coefficient approaching ultralow values (0.06). Superlubricity in carbon nitride is expressed as $\mathrm{C}-\mathrm{N}$ bond breaking for reduced coupling between graphitic-like sheets and eventual $\mathrm{N}_{2}$ desorption. The transforming surface layer acts as a solid lubricant, while the film bulk retains its high elasticity. The present findings offer new means for materials design 
at the atomic level, and for property optimization in wear-critical applications like magnetic reading devices or nanomachines.

TEXT. Carbon-based films attract much attention due to their lubricious properties. ${ }^{1} \mathrm{~N}$ incorporation induces bending and cross-linking of $\mathrm{C}$ basal planes in allotropic structures ${ }^{2-4}$ of carbon nitride $\left(\mathrm{CN}_{\mathrm{x}}\right)$, ascribing highly resilient character to the material. ${ }^{5}$ Depending on the degree of bending and cross-linking, elastic recovery in $\mathrm{CN}_{\mathrm{x}}$ films can reach $\sim 100 \%$, which means no residual indents after retraction of a stationary load. ${ }^{6}$. The optimum $\mathrm{N}$ incorporation for beneficial tribological properties of $\mathrm{CN}_{\mathrm{x}}$ compounds is typically 12 to 16 at. $\%{ }^{6-8}$ Recently, it was demonstrated that ultralow friction in $\mathrm{CN}_{\mathrm{x}}$ is due to weak bonding of the $s p^{2}$-rich surface with the layers below, ${ }^{9}$ with friction coefficients ranging close to the superlubricity region $(<$ 0.05 in $\mathrm{N}_{2}$ atmosphere). ${ }^{10}$ Quoting Erdemir et al., however, "superlubric behavior of $\mathrm{CN}_{\mathrm{x}}$ is still a mystery, but theoretically, it has been proposed that such films can attain a very special surface termination state during the initial conditioning period and then assume a highly chemical inert and non-adhesive sliding behavior in nitrogen environments". ${ }^{11}$

To resolve this mystery, the ultralow friction of $\mathrm{CN}_{\mathrm{x}}$ coatings seems to be related to the presence of a $\mathrm{N}$-free, $s p^{2}$-rich graphitic-like tribolayer, which is thought to form during tribological operation in a process which correlates to "graphitization". ${ }^{12}$ While "graphitization" is usually understood as phase transformation of C-C $s p^{3}$ to C-C $s p^{2}$ bonds in metastable diamond, ${ }^{13,14}$ in our investigations we observe that in $\mathrm{CN}_{\mathrm{x}}$, the film transformation at the surface includes breaking of C-N bonds, $\mathrm{N}$-atom desorption and release of $\mathrm{N}_{2}$. The reduction of $\mathrm{N}$, which decreases the cross-linking and inter-linking sites, leads to superlubricity. 
The lubricious behavior of $\mathrm{CN}_{\mathrm{x}}$ is not affected by surface passivation with $\mathrm{H}$, since $\mathrm{N}$ is bonded with $\mathrm{C}$ dangling bonds. In a recent study, Inoue et al. speculated that tribolayers on macro-scratched $\mathrm{CN}_{\mathrm{x}}$ surfaces would consist only of $\mathrm{C},{ }^{15}$ but its actual composition and nanostructure were not fully interpreted, however, the presence and operation of these tribolayers have not been confirmed at any scale to date. Thus, the lubricious behavior of $\mathrm{CN}_{\mathrm{x}}$ materials awaits experimental verification.

In this study, we have prepared amorphous carbon nitride $\left(\mathrm{a}-\mathrm{CN}_{\mathrm{x}}\right)$ films with a $\mathrm{N}_{2}$ content of $15 \pm 1.5$ at.\% by mid-frequency magnetron sputtering (MFMS) ${ }^{4}$ and assessed their tribological properties at the nanoscale, using a reciprocal nanoscratch test and a diamond conical tip, yielding a point contact between the tip and the film surface. A normal load of $5 \mathrm{mN}$ producing a maximum surface tension of $392.6 \mu \mathrm{N}$ is used, resulting in a high contact pressure of $8.5 \mathrm{GPa}$. Our results show a self-healing effect in a- $\mathrm{CN}_{\mathrm{x}}$ layer exhibiting a low friction coefficient, when tested at ambient temperature $\left(\sim 22{ }^{\circ} \mathrm{C}\right)$ and humidity $(\sim 30 \%)$. This self-healing is accompanied by bond transformations during nanoscratching, including negative wear rate values expressed as material inflation. In the present investigations, the film thickness is $\sim 800 \mathrm{~nm}$, excluding any tribochemical interaction of the $\mathrm{CN}_{\mathrm{x}}$ film with the Si substrate, as reported for ultrathin DLC films by Miyake et al. ${ }^{16}$

The self-healing in $\mathrm{CN}_{\mathrm{x}}$ is exhibited as material inflation at the film surface layers, evidenced by negative values of wear, as shown in Figure 1(a)-1(c) (cf. supporting information). This effect is observed at the first scratching cycles (from $2^{\text {nd }}$ to $10^{\text {th }}$ cycle), as shown in the yellow highlighted areas of Figure 1(a)-1(c). Throughout these cycles, the recovery of the material is higher than its wear, yielding an increase of the average film surface height (magenta circles, Figure 1(b)), relative to the reference surface height (unaffected surface in Figure 1(a)), as 
measured in-situ by scanning probe microscopy (cf. supporting information). This process excludes material pile-up, as described in supporting information. Also, no mating materials effects, such as extrusions, are observed. After $10^{\text {th }}$ cycle, self-healing saturates and simultaneously the wear rate slightly increases until the end of the test. The film surface height remains above the initial surface before scratching and the recovery rate of the surface layers saturates after $20^{\text {th }}$ cycle, suggesting a consistent tribological behaviour of the film (Figure 1(c)). 

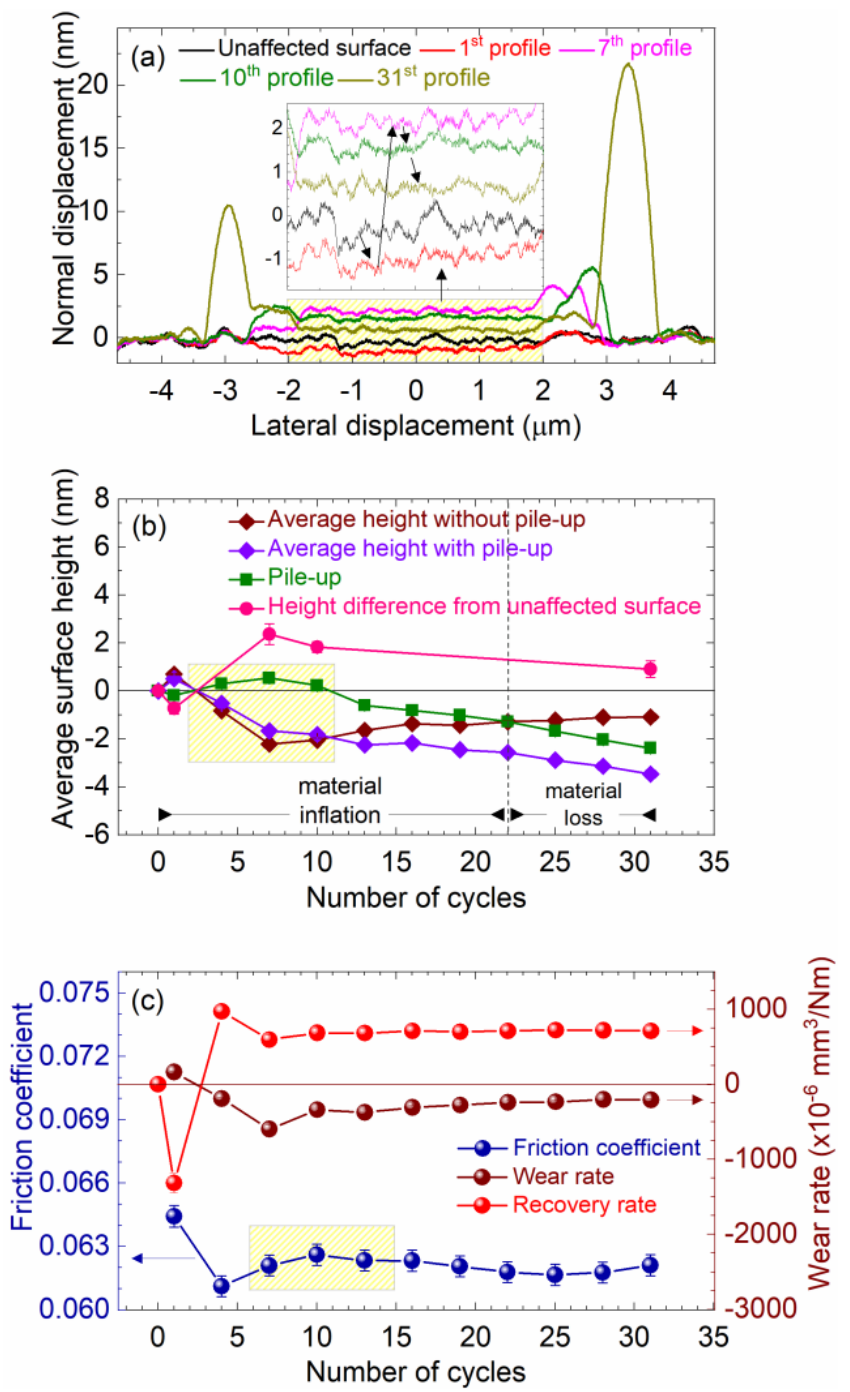

Figure 1. Nanoscratch test of the carbon nitride film. (a) Track profiles recorded before scratching (unaffected surface) and after the $1^{\text {st }}, 7^{\text {th }}, 10^{\text {th }}$, and $31^{\text {st }}$ consecutive cycle, shown as the normal ( $\mathrm{y}$-axis) versus the lateral (x-axis) displacement of the tip. The inset shows the track profiles of Figure 1(a) for $-2<\mathrm{x}<2 \mu \mathrm{m}$. (b) Average surface height including pile-up for $-4<\mathrm{x}$ $<4 \mu \mathrm{m}$ in Figure 1(a) (crimson diamonds), average surface height without pile-up (purple diamonds) for $-2<\mathrm{x}<2 \mu \mathrm{m}$ in Figure 1(a), pile-up at the track borders located at $\mathrm{x}=-3$ and +3.5 $\mu \mathrm{m}$ in Figure 1(a) (green squares), and height differences between initial unaffected surface and track profiles recorded (magenta circles) after $1^{\text {st }}, 7^{\text {th }}, 10^{\text {th }}$, and $31^{\text {st }}$ cycle, as a function of the 
number of cycles. (c) The estimated wear rate of the material excluding pile-up (crimson circles), the estimated recovery rate of the material excluding pile-up (red circles), and the friction coefficient (blue) as a function of the number of cycles. The yellow highlighted areas in Figure 1(c) show the region of the number of cycles in which the friction coefficient decreases again, indicating also the onset of the material inflation.

The changes in material recovery and wear at each cycle are also reflected in friction coefficient variations (blue circles, Figure $1(\mathrm{c})$ ). Between $6^{\text {th }}$ and $15^{\text {th }}$ cycle, friction reaches a maximum (highlighted area in Figure 1(c)) while the lowest negative value of wear rate is obtained at $7^{\text {th }}$ cycle (crimson circles, Figure 1(c)). The negative value of wear can be interpreted as the rate of recovery of the surface, which reaches its maximum value at $4^{\text {th }}$ cycle (red circles, Figure $1(\mathrm{c}))$. The film shows a constant recovery rate after $10^{\text {th }}$ cycle, exhibiting inflation, as observed in Figure 1(a). Nano-debris, acting as third-body, may contribute to friction reduction, as observed up to the $4^{\text {th }}$ cycle, while the increase in friction coefficient up to the $10^{\text {th }}$ cycle is a consequence of nano-debris loss from the contact. ${ }^{17}$ Here, the increment in the friction force up to $10^{\text {th }}$ cycle can be a result of the higher resistance that the tip senses from the transformed top layer during its reciprocal motion. We attribute the observed friction reduction between $10^{\text {th }}$ and $15^{\text {th }}$ cycle to a different lubrication mechanism, governed by surface modifications of the $\mathrm{CN}_{\mathrm{x}}$ film. The mechanism is expressed as phase transformation through tribomechanical interaction (bond-breaking). Friction does not further decrease below 0.061 due to strong bonding of the altered surface layers with the elastic subsurface layers, resisting the tip action. Hence, further evolution of friction depends on the degree of the aforementioned phase transformation (yellow highlighted areas in Figure 1(b) and 1(c)). 
In order to compare the local chemistry of the scratched and unaffected surface layers, we prepared a TEM specimen using focused ion beam (FIB) (Figure 2, cf. supporting information).

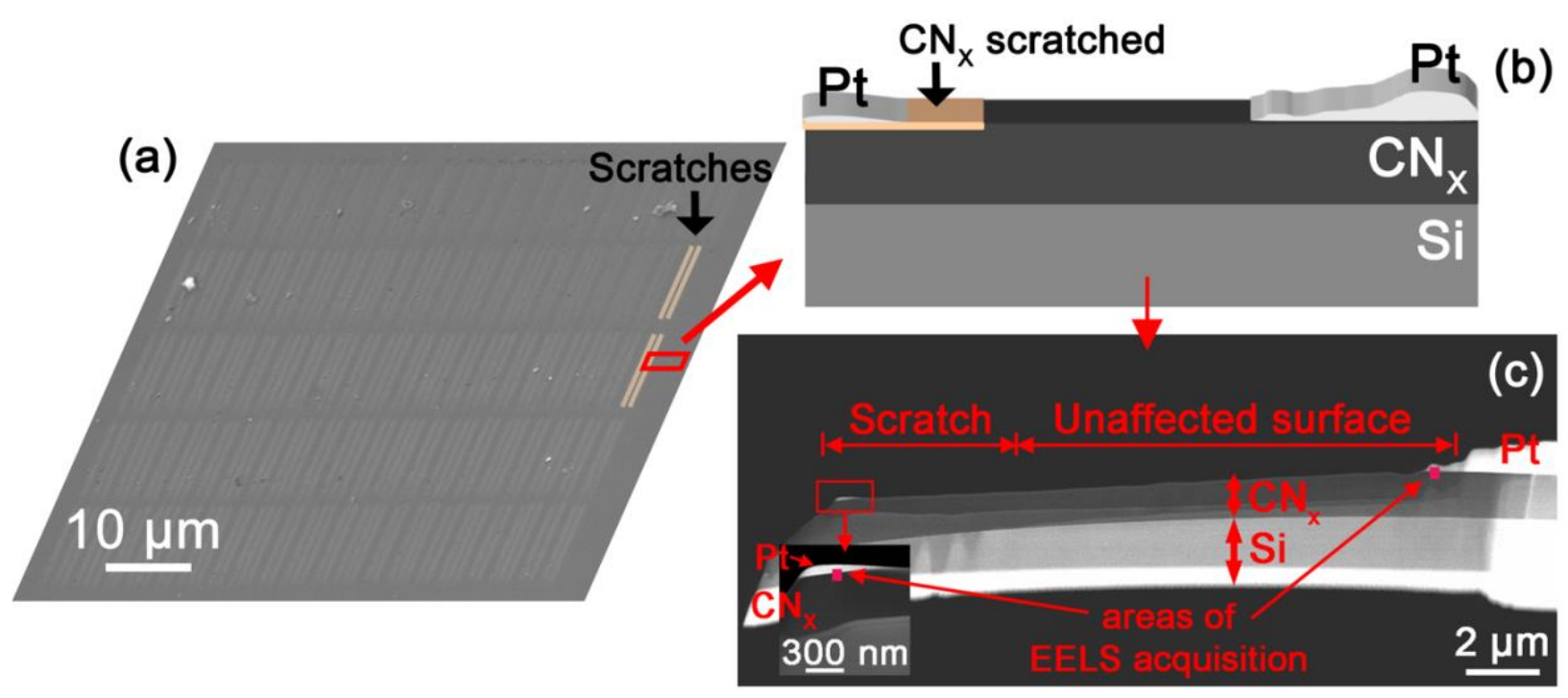

Figure 2. FIB preparation of the TEM specimen. (a) A SEM micrograph of the scratched area ( $50 \times 45 \mu \mathrm{m}$ of multiple scratches) used to obtain the FIB lamella for HRSTEM/EELS analysis of $\mathrm{CN}_{\mathrm{x}}$ film. b) A schematic illustration of the FIB lamella obtained from a part of the film surface (red rectangle in SEM of Figure 2(a)), which included a scratched (in ochre) and an unaffected (in dark grey) area. c) A STEM micrograph of the FIB lamella gripped with Pt by one of the vertical poles of a $\mathrm{Cu}$ grid. The inset in Figure 3(c) shows the part of the scratched surface protected by Pt from which monoEELS spectra were acquired and the red spots indicate the regions of EELS spectra acquisition.

The sample was subsequently investigated by monochromated STEM-EELS, as shown in Figure 3(a)-3(d). The EELS analysis was carried out at identical experimental conditions in four areas of the TEM specimen, denoted as the scratched surface (\#1), below scratched surface (\#2), 
unaffected surface (\#3), and below unaffected surface (\#4). Representative EELS spectra displaying carbon $\mathrm{K}(\mathrm{C}-\mathrm{K})$ and nitrogen $\mathrm{K}(\mathrm{N}-\mathrm{K})$ edges are shown in Figure 3(c) and 3(d), respectively.
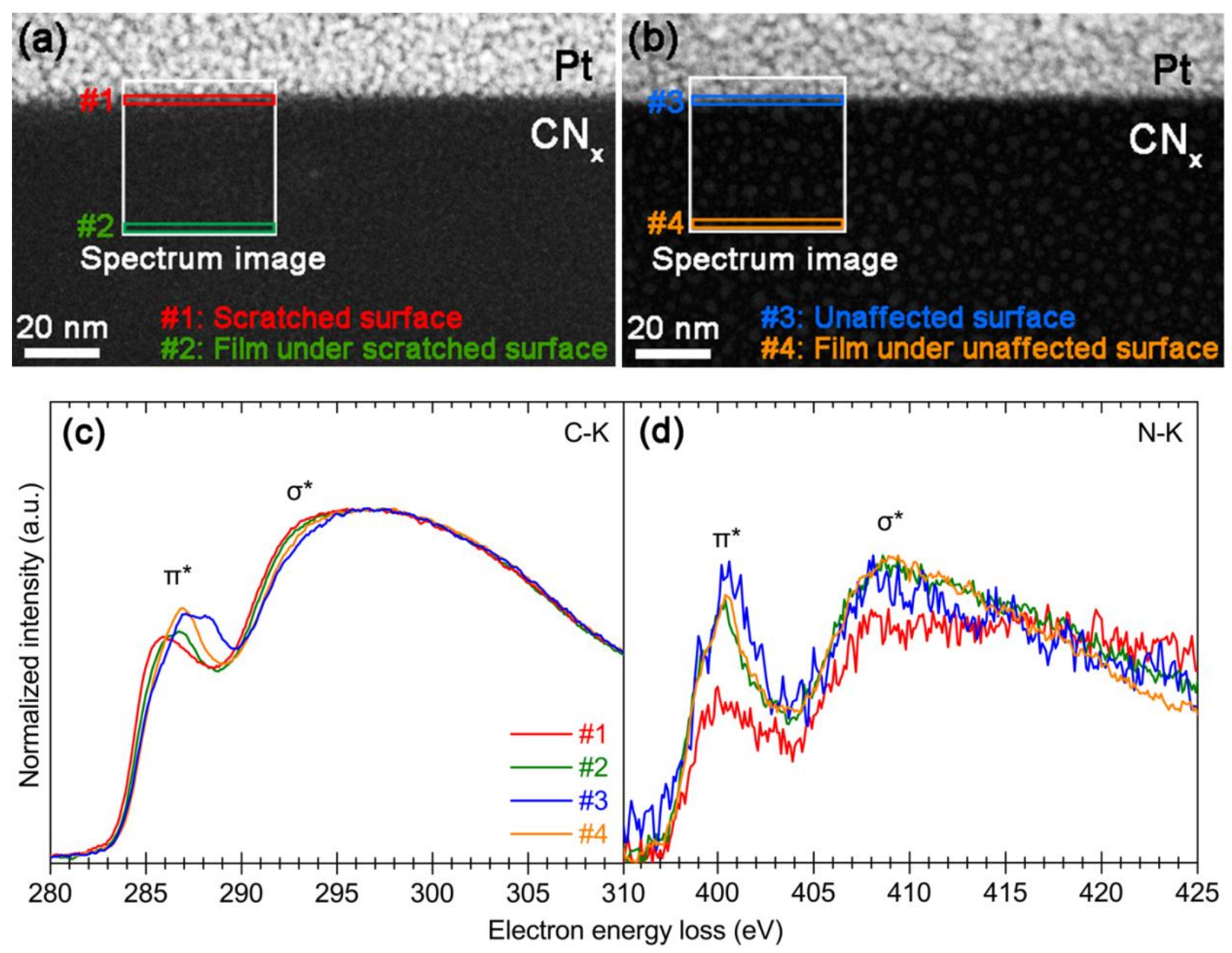

Figure 3. MonoEELS spectra of the scratched and unaffected from scratching surface of the carbon nitride film. HRSTEM micrograph of the Pt/CN $\mathrm{C}_{\mathrm{x}}$ interface of the (a) scratched (marked as $\# 1$ - red) and (b) unaffected (marked as \#3 - blue) surface layers and bulk (marked as \#2 - green and marked as \#4 - orange, respectively) $\mathrm{CN}_{\mathrm{x}}$. White squares denote the areas of the monochromated EELS (monoEELS) spectra acquisition and the colored rectangles, the areas where the average monoEELS spectra were obtained from. (c) MonoEELS spectra of C-K and 
(d) N-K edge obtained from the scratched surface layer (\#1), an area underneath it (\#2), the unaffected surface layer (\#3), and an area underneath it (\#4).

The C-K edge EELS spectra exhibit pronounced near-edge fine structure, consisting of a sharp initial peak in the range of $285.7-287.1 \mathrm{eV}$, followed by a broader and more intense peak centered at $\sim 290.9 \mathrm{eV}$ (Figure 3(c)). These peaks are well-known to represent transitions from the $\mathrm{K}$ core level to $\pi^{*}\left(1 \mathrm{~s} \rightarrow \pi^{*}\right)$ and $\sigma^{*}$ states $\left(1 \mathrm{~s} \rightarrow \sigma^{*}\right)$, respectively. ${ }^{18}$ It is further established that the relative integrated peak areas provide an accurate estimate of the ratio between $s p^{2}$ and $s p^{3}$ hybridization of carbon in the material. ${ }^{18}$ As evidenced from Figure 3(c), the $\sigma^{*}$ peak is identical in all layers indicating little variation in the $s p^{3}$-bound $\mathrm{C}$ environment.

However, a difference among the $\mathrm{C}-\mathrm{K}$ edge profiles is observed in the intensity and in the fine structure of the $\pi^{*}$ peak, indicating variations in the $s p^{2}$ bonding environment. Most importantly, both spectra under the scratched surface exhibit a smaller $\pi^{*}$ peak, indicating a reduced $s p^{2} / s p^{3}$ ratio. While the edge onset is similar for all spectra, the scratched surface spectrum (\#1) $\pi^{*}$ peak maximum exhibits a $0.8-1.4 \mathrm{eV}$ redshift, compared to the spectrum under the unaffected surface (\#4), which is used as reference, as it is unaffected by scratching and any unintentional surface modification.

The nature of these changes was further addressed by analyzing the corresponding $\mathrm{N}-\mathrm{K}$ edge, as shown in Figure 3(d). The spectra exhibit a notably poorer signal-to-noise ratio, due to the lower $\mathrm{N}$ concentration and smaller EELS scattering cross-section compared to the C-K edge. In analogy to $\mathrm{C}$, the N-K edge exhibits a $\pi^{*}$ peak at $400 \mathrm{eV}$ and a $\sigma^{*}$ peak at $407 \mathrm{eV}$. The most pronounced difference among the $\mathrm{N}-\mathrm{K}$ edge fine structures is the reduced intensity in the scratched surface layer (\#1) edge, identifying a reduced $\mathrm{N}$ content compared to the other spectra, 
which indicates a breaking of the original $\mathrm{C}-\mathrm{N}$ bonds and a subsequent removal of $\mathrm{N}$ atoms, potentially through $\mathrm{N}_{2}$ desorption. Additionally, the reduced $\mathrm{N} \pi^{*}$ peak intensity indicates a slightly lower $s p^{2}$ bond content among the remaining $\mathrm{N}$ atoms. Consequently, the $\mathrm{C}-\mathrm{N}$ bond breaking and removal of $\mathrm{N}$ occurs preferentially in $s p^{2}$-bound $\mathrm{N}$. However, quantification of the $\mathrm{N}-\mathrm{K}$ edge shows a $\mathrm{N}$ content of $\sim 15 \pm 1.5$ at.\% on the surface, showing that the changes in the content of $\mathrm{N}$ lie in the statistical error (cf. supporting information, $\mathrm{N}$ content in the film is $\sim 15 \pm$ 1.5 at.\%). Under the scratched surface (spectrum \#2), the $\mathrm{N}$ bond environment appears similar to the unaffected material. This suggests that the reduced $s p^{2}$ content, which was observed in the C$\mathrm{K}$ spectrum for the indented material, is exclusively related to a $s p^{2}-t o-s p^{3}$ transformation in the C-C bonds.

The loss of $\mathrm{N}$ from the $s p^{2}$-bound material near the surface causes the reduction of the number of cross-links between $\mathrm{CN}_{\mathrm{x}}$ sheets ${ }^{8}$ and therefore, the material swells. This local expansion of material is very likely to be accompanied by a relief of the surface layers from residual stress. The $\mathrm{CN}_{\mathrm{x}}$ film possesses a very high residual stress of $4.2 \mathrm{GPa}$, corresponding to a stored elastic energy of $1.38 \times 10^{-10} \mathrm{eV} / \mathrm{nm}^{3}$. This energy is released during scratching, since such energy amount can be introduced locally at the wear track as kinetic energy transferred from the tip to the material, which may be approximately given as $K \sim 460 \times 10^{-15} \mathrm{~J}=2.87 \times 10^{-6} \mathrm{eV}$. In comparison, the resulting increase in $s p^{3}$-bound $\mathrm{C}$ under the scratched surface is not expected to affect the density of the material significantly. The remaining $\mathrm{N}$-deficient sheets are also presumed to maintain their $s p^{2}$-bound nature and assume increasingly graphitic properties. The reduced cross-linking in the scratched surface is further expected to enable slip on the $s p^{2}$-bound sheets. This can additionally explain the friction values of this film, which are very close to the ultralow friction region, as well as its excellent wear resistance, including self-healing. This is 
beneficial for the wear performance of $\mathrm{CN}_{\mathrm{x}}$, where relatively little material is sacrificed from the surface.

The atomic rearrangement at the surface of $\mathrm{CN}_{\mathrm{x}}$, due to bond transformation, is verified from density functional theory (DFT) calculations (Figure 4(a)-4(d)). Our modelling results discussed below illustrate a more representative view of the bonding transformation in the vicinity of $s p^{2}$ hybridized $\mathrm{N}$ that eventually desorbs as $\mathrm{N}_{2}$ weakly bonded to $\mathrm{C}$ atom of the $\mathrm{CN}_{\mathrm{x}}$ surface. ${ }^{19}$ The theoretically estimated enthalpy for bond transformation is $0.02 \mathrm{eV} /$ at. This value is larger by an order of magnitude than the thermal energy at moderate temperature $\left(\sim 300{ }^{\circ} \mathrm{C}\right)$. As mentioned above, this amount of energy may be introduced at the wear track during scratching as kinetic energy, transferred from the tip to the film $\left(K \sim 2.87 \times 10^{-6} \mathrm{eV}\right)$. Considering that the diameter of the contact area between the tip and the surface is $\sim 5 \mu \mathrm{m}$, the number of affected atoms (depth of $\sim 10$ atomic layers considered) corresponding to the size of the wear track is $\sim 10^{8}$ atoms, giving a share of $\sim 0.02 \mathrm{eV} / \mathrm{at}$ of the transferred kinetic energy. This estimation matches remarkably well the energy cost for the bond transformation reflected in the transition from MS1 to MS2 (Figure 4(a) and 4(b), respectively), which corresponds to a $s p^{2}$-to-s $s p^{3}$ transition. This corroborates as feasible that the kinetic energy transferred during scratching from the tip to the track would suffice to cause significant local restructuring, including removal of cross(inter)linkages between sheets. 


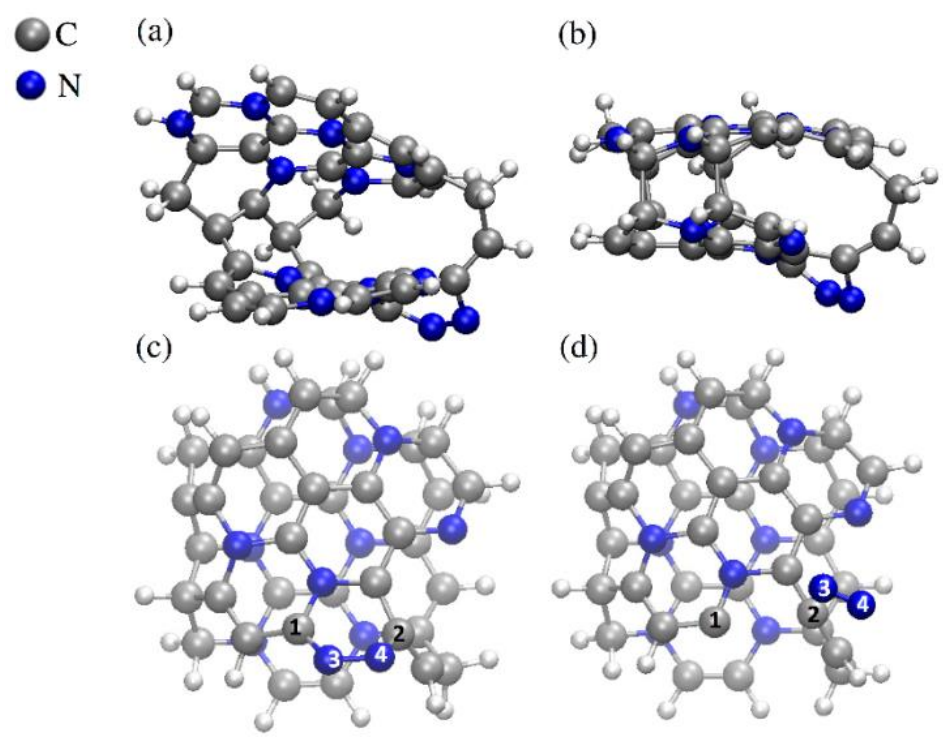

Figure 4. Optimized $\mathrm{CN}_{\mathrm{x}}$ model systems of stoichiometry $\mathrm{C}_{36} \mathrm{~N}_{12} \mathrm{H}_{21}$ : (a) $\mathrm{MS} 1$, system exhibiting a surface rich in $s p^{2}$-type links; (b) MS2, system containing cross-linkages or $s p^{3} \mathrm{C}$ atoms bonded to $\mathrm{N}$ atoms; (c) MS3, system before a possible $\mathrm{N}_{2}$ desorption; (d) MS4, system resulting from MS3 and releasing a $\mathrm{N}_{2}$ molecule weakly bonded to a $\mathrm{C}$ atom.

The $\mathrm{CN}_{\mathrm{x}}$ bond transformation, resulting from sufficient energy introduced to the surface layer and leading to material inflation (Figure 1(a)-1(d)), can be also understood from these theoretical calculations. We estimate the structural rearrangements using a $\mathrm{CN}_{\mathrm{x}}$ model system (MS) in two situations: (i) from a less cross-linked configuration (MS1) to a more cross-linked configuration (MS2), as displayed in Figure 4(a)-4(b); and (ii) after "single act/pure" $\mathrm{N}_{2}$ desorption (MS3 to MS4 transformation), as shown in Figure 4(c)-4(d), where the MS stoichiometry obviously changes. In both MS1-to-MS2 and MS3-to-MS4 transformations, the structural changes may be related to a reduction in the $s p^{2} / s p^{3}$ ratio. In MS1-to-MS2 transition, bond transformation due to rearrangement, stemming from the cross-linkage removal, can be energetically favored because of the small energy difference ( $0.02 \mathrm{eV} / \mathrm{at})$ between MS1 and MS2. Furthermore, the possible 
energy desorption of $\mathrm{N}_{2}$ is slightly larger $(0.026 \mathrm{eV} / \mathrm{at})$ and leads to a very significant local inflation by nearly $1 / 3$ of the initial volume. In reality, during scratching, bond rearrangement and nitrogen desorption certainly co-occur, as experimentally verified by monoEELS in Figure 3(a)-3(d)), contributing towards bond and structural transformations when sufficient energy is introduced to the system.

In conclusion, we report material inflation in $\mathrm{CN}_{\mathrm{x}}$ films, operating as self-healing material and resolve an intriguing question on superlubricity. The self-healing in $\mathrm{CN}_{\mathrm{x}}$ is explained by surface associated $\mathrm{C}-\mathrm{N}$ bond breaking, leading to cross-linking removal and $\mathrm{N}_{2}$ desorption upon scratching. In the vicinity of the disrupting $\mathrm{C}-\mathrm{N}$ bonds, the structure swells and adopts graphiticlike properties, causing the layers to increasingly act as a solid lubricant at the nanoscale, which reduces friction. Simultaneously, the subsurface layers remain more or less intact, with some observation of an increasingly $s p^{3}$-rich structure, pertaining high wear resistance. The appearance of self-healing in $\mathrm{CN}_{\mathrm{x}}$ is a unique characteristic observed for the first time in a C-based material and can be used to increase the performance, reliability, and wear resistance of components, in machinery and data memory devices from nano- to macroscale, including specifically hard disk drives.

\section{ASSOCIATED CONTENT}

Supporting Information. Synthesis of the $\mathrm{CN}_{\mathrm{x}}$ film, nanotribological tests and determination of recovery and wear rate as well as friction coefficient, FIB preparation of the TEM specimen, high-resolution STEM and monochromated EELS, and DFT simulations (PDF). 


\section{AUTHOR INFORMATION}

\section{Corresponding Author}

*Konstantinos Bakoglidis. E-mail: konstantinos.bakoglidis@manchester.ac.uk, bakoglidis.konstantinos@ gmail.com, ORCID: http://orcid.org/0000-0003-2274-5962.

*Lars Hultman. E-mail: larhu@ifm.liu.se.

\section{Present Addresses}

I(K.D.B.) School of Materials, The University of Manchester, Manchester M13 9PL, UK.

\section{Author Contributions}

LH supervised the study that was jointly conceived by LH and KDB. KDB conducted the film synthesis, nanotribology, FIB lamella preparation, XPS analyses, with input from LH. POÅP and LH oversaw HRSTEM and EELS analysis performed by JP. GKG, RBS, and RR developed the model systems and modelling procedure as well as performed the DFT calculations. KDB and LH wrote the manuscript with contributions from the other coauthors. All coauthors read and commented on successive drafts of the manuscript.

\section{Funding Sources}

LH received funding from VINN Excellence Center Functional Materials (project no. FunMat 2005-02987). GKG, RSsS, and RR received partial financial support from the Swedish Research Council (project no. 348-2014-4249). PÅP received funding from the Swedish Research Council through projects 621-2012-4359, 621-2012-4420, 622-2008-405. GKG received funding from the Swedish Foundation for Strategic Research through the project RMA11-0029 on Functional 
Carbides and Advanced Surface Engineering (FUNCASE), the FLAG-ERA JTC 2015 project

GRIFONE, and Carl Tryggers Foundation for Scientific Research (project no. CTS 16:165). LH and PÅP received funding from the Swedish Government Strategic Research Area in Materials Science on Advanced Functional Materials (SFO-Mat-LiU 2009-00971) and from Knut and Alice Wallenberg Foundation for supporting the Linköping Electron Microscopy Laboratory (project no. KAW 2008-0058). LH received a Scholar Grant from Knut and Alice Wallenberg Foundation (project number KAW 2011-0143.

\section{Notes}

The authors declare no competing financial interest.

\section{ACKNOWLEDGMENTS}

The VINN Excellence Center Functional Materials (FunMat 2005-02987) is acknowledged. G.K. Gueorguiev, R.S. dos Santos, and R. Rivelino acknowledge partial financial support for this work by Swedish Research Council (VR) through the Swedish Research links project 348-20144249. P.O.Å Persson acknowledges the Swedish Research Council through projects 621-20124420, 621-2012-4359, and 622-2008-405. G.K. Gueorguiev acknowledges the support by Swedish Foundation for Strategic Research (SSF) Synergy Grant No. RMA11-0029 on Functional Carbides and Advanced Surface Engineering (FUNCASE). L. Hultman and P.O. $\AA$ Persson acknowledge the Swedish Government Strategic Research Area in Materials Science on Advanced Functional Materials at Linkoping University (SFO-Mat-LiU 2009-00971) and the Knut and Alice Wallenberg Foundation for supporting the Linköping Electron Microscopy 
Laboratory (KAW 2008-0058) and a Scholar Grant for L. Hultman (KAW 2011-0143). Grzegorz

Greczynski is acknowledged for his support to x-ray photoelectron spectroscopy analyses and

Susann Schmidt is acknowledged for her support during the synthesis of the materials.

\section{REFERENCES}

(1) Erdemir, A.; Ramirez, G.; Eryilmaz, O. L.; Narayanan, B.; Liao, Y.; Kamath, G.; Sankaranarayanan, S. K. R. S. Carbon-Based Tribofilms from Lubricating Oils. Nature 2016, 536 (7614), 67-71.

(2) Hellgren, N.; Macák, K.; Broitman, E.; Johansson, M. P.; Hultman, L.; Sundgren, J. Influence of Plasma Parameters on the Growth and Properties of Magnetron Sputtered CN X Thin Films Influence of Plasma Parameters on the Growth and Properties of Magnetron Sputtered CN X Thin Films. J. Appl. Phys. 2003, 524 (2000), 524.

(3) Shimoyama, I.; Wu, G.; Sekiguchi, T.; Baba, Y. Study of Electronic Structure of

Graphite-like Carbon Nitride. J. Electron Spectros. Relat. Phenomena 2001, 114-116, $841-848$.

(4) Bakoglidis, K. D.; Schmidt, S.; Garbrecht, M.; Ivanov, I. G.; Jensen, J.; Greczynski, G.; Hultman, L. Low-Temperature Growth of Low Friction Wear-Resistant Amorphous Carbon Nitride Thin Films by Mid-Frequency, High Power Impulse, and Direct Current Magnetron Sputtering. J. Vac. Sci. Technol. A Vacuum, Surfaces, Film. 2015, 33 (5), $05 \mathrm{E} 112$.

(5) Neidhardt, J.; Hultman, L.; Broitman, E.; Scharf, T. W.; Singer, I. L. Structural, Mechanical and Tribological Behavior of Fullerene-like and Amorphous Carbon Nitride 
Coatings. Diam. Relat. Mater. 2004, 13, 1882-1888.

(6) Hultman, L.; Neidhardt, J.; Hellgren, N.; Sjöström, H.; Sundgren, J.-E. Fullerene-like Carbon Nitride: A Resilient Coating Material. MRS Bull. 2003, 28 (March), 194-202.

(7) Scharf, T. W.; Ott, R. D.; Yang, D.; Barnard, J. A. Structural and Tribological Characterization of Protective Amorphous Diamond-like Carbon and Amorphous CNx Overcoats for next Generation Hard Disks. J. Appl. Phys. 1999, 85 (1999), 3142.

(8) Gueorguiev, G. K.; Neidhardt, J.; Stafström, S.; Hultman, L. First-Principles Calculations on the Curvature Evolution and Cross-Linkage in Carbon Nitride. Chem. Phys. Lett. 2005, $410,228-234$.

(9) Cui, L.; Lu, Z.; Wang, L. Exploring the Low-Friction Mechanism of CNx Films in Inert Atmospheres by First-Principles Calculations. Appl. Surf. Sci. 2015, 356, 1082-1085.

(10) Kato, K.; Umehara, N.; Adachi, K. Friction, Wear and N2-Lubrication of Carbon Nitride Coatings: A Review. Wear 2003, 254 (11), 1062-1069.

(11) Erdemir, A.; Eryilmaz, O. Achieving Superlubricity in DLC Films by Controlling Bulk, Surface, and Tribochemistry. Friction 2014, 2 (2), 140-155.

(12) Voevodin, A. A.; Jones, J. G.; Back, T. C.; Zabinski, J. S.; Strel'nitzki, V. E.; Aksenov, I. I. Comparative Study of Wear-Resistant DLC and Fullerene-like CNx Coatings Produced by Pulsed Laser and Filtered Cathodic Arc Depositions. Surf. Coatings Technol. 2005, 197, 116-125.

(13) Franklin, R. E. Homogeneous and Heterogeneous Graphitization of Carbon. Nature 1956, 
(14) Seal, M. Graphitization of Diamond. Nature 1960, 185, 522-523.

(15) Wang, P.; Adachi, K. Low Frictions of Self-Mated CNx Coatings in Dry and Humid Inert Gas Environments. Surf. Coatings Technol. 2014, 258, 1137-1144.

(16) Miyake, S.; Yamazaki, S. Evaluation of Protuberance and Groove Formation in Extremely Thin DLC Films on Si Substrates due to Diamond Tip Sliding by Atomic Force Microscopy. Wear 2014, 318 (1-2), 135-144.

(17) Singer, I. L.; Dvorak, S. D.; Wahl, K. J.; Scharf, T. W. Role of Third Bodies in Friction and Wear of Protective Coatings. J. Vac. Sci. Technol. A 2003, 21 (5), S232-S240.

(18) Robertson, J. Diamond-like Amorphous Carbon. Mater. Sci. Eng. R Reports 2002, 37, $129-281$.

(19) Mane, G. P.; Talapaneni, S. N.; Lakhi, K. S.; Ilbeygi, H.; Ravon, U.; Al-Bahily, K.; Mori, T.; Park, D. H.; Vinu, A. Highly Ordered Nitrogen-Rich Mesoporous Carbon Nitrides and Their Superior Performance for Sensing and Photocatalytic Hydrogen Generation. Angew. Chemie - Int. Ed. 2017, 56 (29), 8481-8485.

BRIEFS 
Carbon nitride offers superlubricity through self-healing. The surface layers of the films act as solid lubricants, showing a surface inflation; a notable phenomenon observed for the first time in carbon-based films at the nanoscale.

\section{SYNOPSIS}

Superlubricity is a solution to high wear for many tribological applications and is provided by ultralow-friction thin films deposited on components. Carbon nitride offers superlubricity and self-healing properties. In this conditions, the surface layers of the films act as solid lubricants, showing a surface inflation; a notable phenomenon observed for the first time in carbon-based films at the nanoscale.

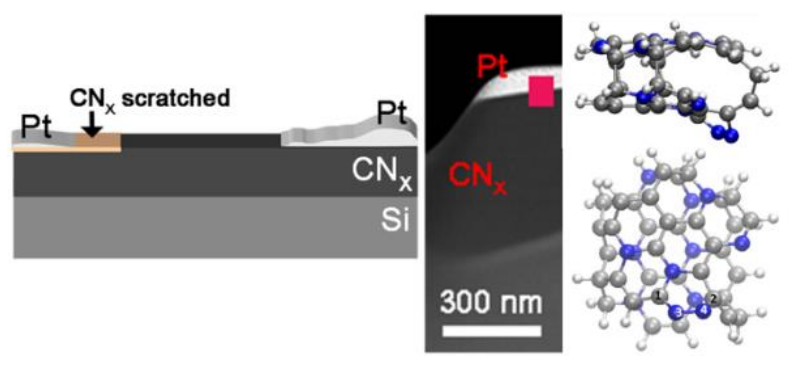

Graphical abstract for ToC 